\title{
Dispatching Design for Customized Bus of Hybrid Vehicles Based on Reservation Data
}

\author{
Xuemei Zhou $\mathbb{D},{ }^{1}$ Jiaojiao Xi $\mathbb{D},{ }^{1}$ Zhen Guan $\mathbb{D},{ }^{1}$ and Xiangfeng Ji $\mathbb{D}^{2}$ \\ ${ }^{1}$ College of Transportation Engineering, Key Laboratory of Road and Traffic Engineering of the State Ministry of Education, \\ Shanghai Key Laboratory of Rail Infrastructure Durability and System Safety, Tongji University, 4800 Caoan Highway, \\ Shanghai 201804, China \\ ${ }^{2}$ Department of Management Science and Engineering, School of Business, Qingdao University, \\ 62 Keda Branch Road, Laoshan District, Qingdao 266000, China
}

Correspondence should be addressed to Jiaojiao Xi; 1910957@tongji.edu.cn

Received 1 September 2020; Revised 8 September 2021; Accepted 23 November 2021; Published 20 December 2021

Academic Editor: Ricardo Giesen

Copyright ( 2021 Xuemei Zhou et al. This is an open access article distributed under the Creative Commons Attribution License, which permits unrestricted use, distribution, and reproduction in any medium, provided the original work is properly cited.

Proper vehicle operation and route planning are critical for achieving the best match between bus operation and passenger services. In order to enhance the attractiveness of public transportation, a new type of the public transportation dispatching method based on passenger reservation data is proposed. This mode can meet the requirements of multiple lines in urban centers during peak hours, which can realize direct service between two stations. Then, taking the lowest operating cost of the enterprise and the lowest passenger waiting cost as the optimization goal, a customized dynamic dispatching model of multiline and hybrid vehicles was established. Finally, a calculation example is designed and the genetic algorithm is used to solve the model. The results show that the hybrid vehicle solution is more reasonable than the traditional single-vehicle solution and reveal that the model is feasible to optimize scheduling plan. The conclusions obtained in this research lay a theoretical foundation for APP setup and operation plan formulation.

\section{Introduction}

With the improvement of Internet technology and the realization of intelligent means, some scholars have focused on the study of customized bus dispatch on the basis of conventional bus dispatch [1-4]. However, there are still problems in custom-made buses, such as high operating costs for enterprises and lack of theoretical guidance in vehicle operation and route planning $[5,6]$.

Over the past decades, customized buses have become a form of ridesharing with the improvement of the Internet and information methods, which is one of the effective urban traffic supply and demand management policies to reduce car ownership and mitigate traffic congestion [7]. For example, Ma et al. [8] formulated necessary ride matching constraints for participants of multiple ridesharing services and proved the rationality of route selection based on the OD pricing strategy. Liu et al. [9] developed precise and approximate algorithms to optimize large-scale bus ridesharing services, which greatly reduce the number of vehicles compared with car ridesharing.

On this basis, some scholars have studied the application of modular vehicles in public transport operations. For example, Caros and Chow [10] analyzed three types of service designs using modular autonomous vehicles (MAVs). The aim is to reflect the impact of transfers on the way to users and operators under different last-mile service designs. Zhang et al. [11] evaluated the advantages of modular vehicles in improving public transportation. Liu et al. [12] used the deficit function to solve the minimum fleet size of modular vehicles in the public transportation system. Pei et al. [13] proposed the concept of modular transportation network system (MTNS) to overcome the mismatch between the fixed vehicle capacity and the changing travel demand of space in the traditional public transportation system. Liu et al. [14] developed a two-stage 
solution to improve flex-route transit services. Gong et al. [15] proposed a modular bus system design method that can optimize passenger route allocation.

The above research studies are analyzed from the perspective of vehicle automation technology application [16], which provides services effectively by selecting the appropriate ratio of trailers and main modules [17]. Different from this, some scholars have adopted some smart scheduling strategies from the perspective of company operations and management to increase the attractiveness of customized buses. For example, Nourbakhsh and Ouyang [18] proposed an alternative flexible route bus system based on the optimal network layout. Qiu et al. [19] proposed a dynamic site strategy to effectively reduce user costs. Neven et al. [20] assessed the impact of different demand response transportation systems (DRT) on policy decisions for people with disabilities. Dell'Olio et al. [21] constructed a two-level planning model for the optimization of departure frequency and vehicle type.

The above research studies only specifically studied the scheduling methods and models of single-vehicle flexible bus routes. In fact, the choice of vehicle types can be diversified. Considering the cost-effectiveness and resource integration, the following studies have further explored the hybrid vehicle types.

Zhou et al. [22] established a multiobjective bi-level planning model for collaborative optimization for the hybrid formation of electric buses and traditional buses. Sun et al. [23] tried to use multitype buses to solve the flexible demand of single-line passengers problem. Yao et al. [24] proposed a new method to solve the electric vehicle scheduling problem based on a given multivehicle type schedule. Li et al. [25] proposed a solution to the multisite vehicle scheduling problem with multiple vehicle types (MVTs) under range and refueling constraints. Hassold and Ceder [26] proposed a network traffic model based on minimum cost to solve the multivehicle scheduling problem (MVT-VSP) which was effectively verified in a real case in Auckland, New Zealand. Ellegood et al. [27] provided a general strategic analysis using continuous approximation models to assess the conditions under which mixed loading is likely to be beneficial. Wang et al. [28] focused on the bus bridging problem under operational disruptions on a single metro line. A multiobjective optimization model is established with objectives to minimize total waiting time, the number of stranded passengers, and dispatched vehicles. Zhang et al. [29] used the enumeration method to establish a planning model that simultaneously optimizes bus types and schedules.

The research studies in the above literature mainly focus on a single route and lack further expansion on multiple routes. In response to this phenomenon, the following studies have made corresponding supplements and extensions.

Lu et al. [30] proposed a new operational mode to serve passengers on both street sides. In addition, when multiple feeder buses are operating in the target service area, the proposed model can provide an optimal plan to locate the nearest one to response to the demands. Liu et al. [31] proposed hybrid operation modes that combine fixed and dynamic frequencies in a bimodal period, which optimizes the fleet size and schedules of feeder buses that connect metro and residential areas in the context of bike-sharing systems. Some scholars studied demand-responsive connection bus route planning to minimize the waiting time and riding time of passengers, which can solve the problem of "last-mile" transfer between bus stations and subway stations [32, 33].

Summarizing all the above studies, some scholars focus on modularized vehicles for customized public transportation and some formulate scheduling strategies from the perspective of operation management. This study is inclined to the latter. The differences from previous studies are as follows:

(1) In the past, these studies on multiple lines and multiple vehicles focused on the transfer between stations and the last-mile line service. For urban centers where there is currently no subway, it is necessary to consider a system with point-to-point service.

(2) For the first time, this study integrates the operation modes of buses, subways, and taxis and provides a new operation strategy and management perspective for solving the oversaturated traffic problem in urban centers.

Therefore, in order to increase the attractiveness of public transportation and improve the service quality of public transportation enterprises, a new type of public transportation mode for direct appointment between stations is proposed. This study combines the reservation mode of taxis and takes the passenger flow of subway stations as a reference. It has the advantages of fast, punctual, and lowcost travel. The research perspective is as shown in Figure 1.

\section{Process Analysis of Customized Bus Dynamic Dispatch System}

The customized bus dispatching system can realize the information interaction between passengers and buses, and it responds to the scheduled station in time based on the regular route. It is oriented to areas with dense urban passenger flow. The dispatching process and the line situation in the area are shown in Figure 2.

(1) Customized bus dynamic dispatch is based on the taxi travel reservation mode. The sample value of the station passenger flow in this study is combined with the design characteristics of the bus station and referenced the peak hour passenger flow of the ground station and elevated station of the subway stations [34, 35].

(2) Mobile phones or computers are used to dynamically reserve travel requirements (reservation starting point, number of reservations, and destination site) on the APP terminal. After the dispatch center responds, it selects a reasonable type (three types of fixed-rate vehicles). There are 12 stations in an area in the red line frame in Figure 2, and $\mathrm{A} \sim \mathrm{L}$, 


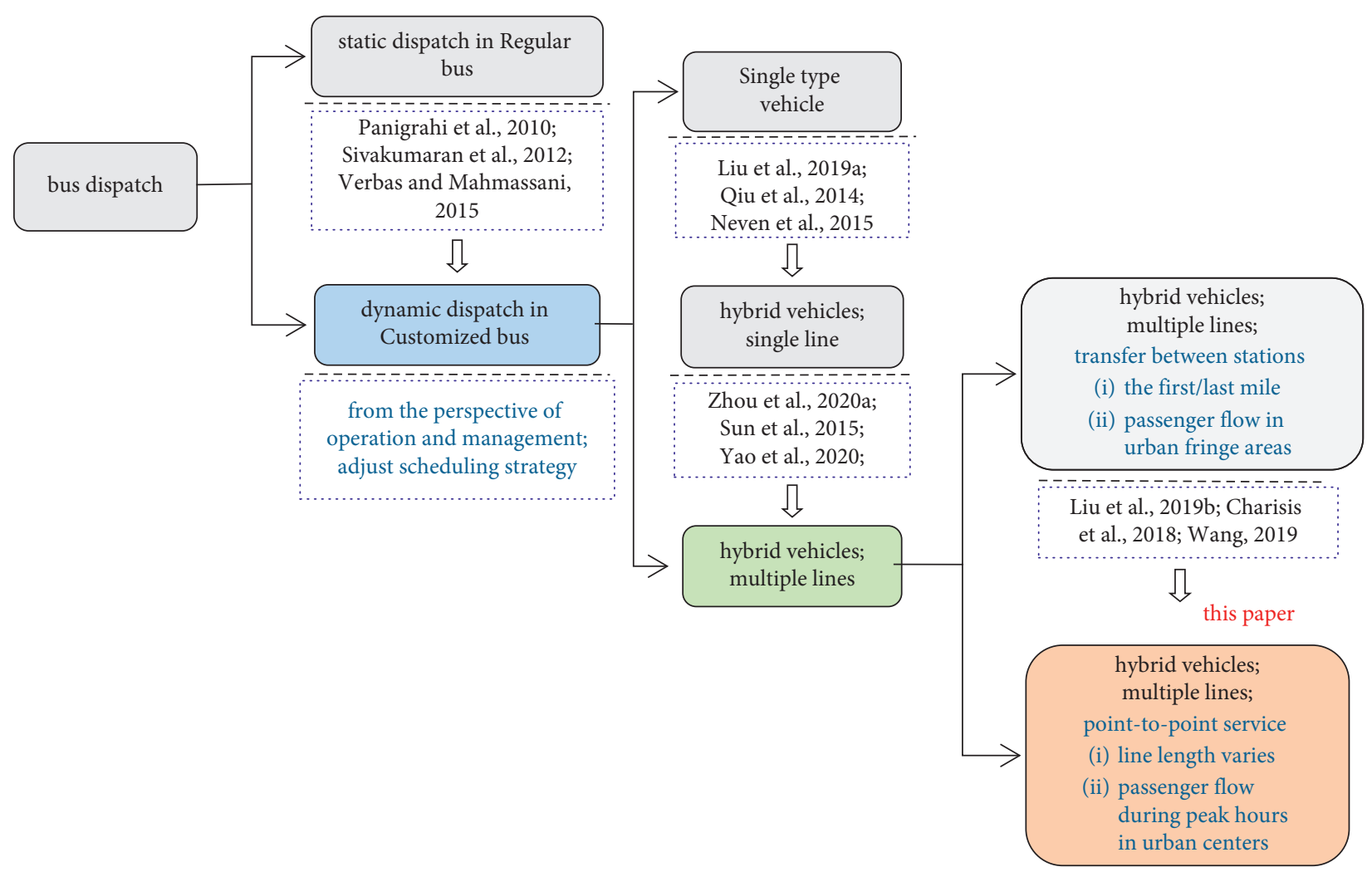

Figure 1: Research direction of bus dispatch.

respectively, represent their station numbers. The distance between every two stations is known, and passengers can make an appointment to get on or get off at any station. Finally, the optimization goal is to minimize the operating cost of the company and the cost of passenger waiting so as to maximize the overall benefits of passengers and bus companies.

(3) Under the customized dynamic bus dispatching mode, the optimal multiline hybrid vehicle combination plan can be finally obtained and a reasonable dispatching operation plan can be formulated.

\section{Customized Bus Dynamic Dispatch Model Construction}

3.1. Basic Assumption. The process of the customized bus dynamic dispatch system for passenger reservations is analyzed, and the line conditions are combined in the area in Figure 2; the basic assumptions are as follows:

(1) Single direction operation means that only the oneway operation of the vehicle is considered.

(2) The distance between any two stations is known.

(3) Passenger demand is known; that is, the number of people getting on and off at each station is known. And passengers getting on and off at each station are random and independent of each other.

(4) The dispatch center completes the dispatch of vehicles and drivers within 3 minutes.
(5) The vehicles provide point-to-point services without stopping in the middle station based on passenger reservations.

(6) In this study, passenger reservation requirements are all corresponding. Passengers can make dynamic reservations during the appointment time period of APP, except for the last time node, which cannot be cancelled.

(7) Passengers can enter the station to check the ticket with the reservation code during the reserved time period. The arrival time of passengers can be read by the data of the inbound ticket gate.

3.2. Model Parameters. The meanings of the main parameters and decision variables in the model are shown in Table 1 .

3.3. Model Building. The customized dynamic dispatching model of multiline hybrid vehicles is as follows:

(1) Operating cost of bus companies is as follows:

$$
f_{1}=\sum_{i} \sum_{j} \sum_{k} c_{k}^{f} x_{i j k}+\sum_{i} \sum_{j} \sum_{k} c_{k}^{f} x_{i j k} d_{i j} .
$$

(2) Waiting cost for passengers at stations is as follows:

$$
f_{2}=\sum_{l} \sum_{i} c_{w} t_{l i}^{w} n_{i}^{p}
$$




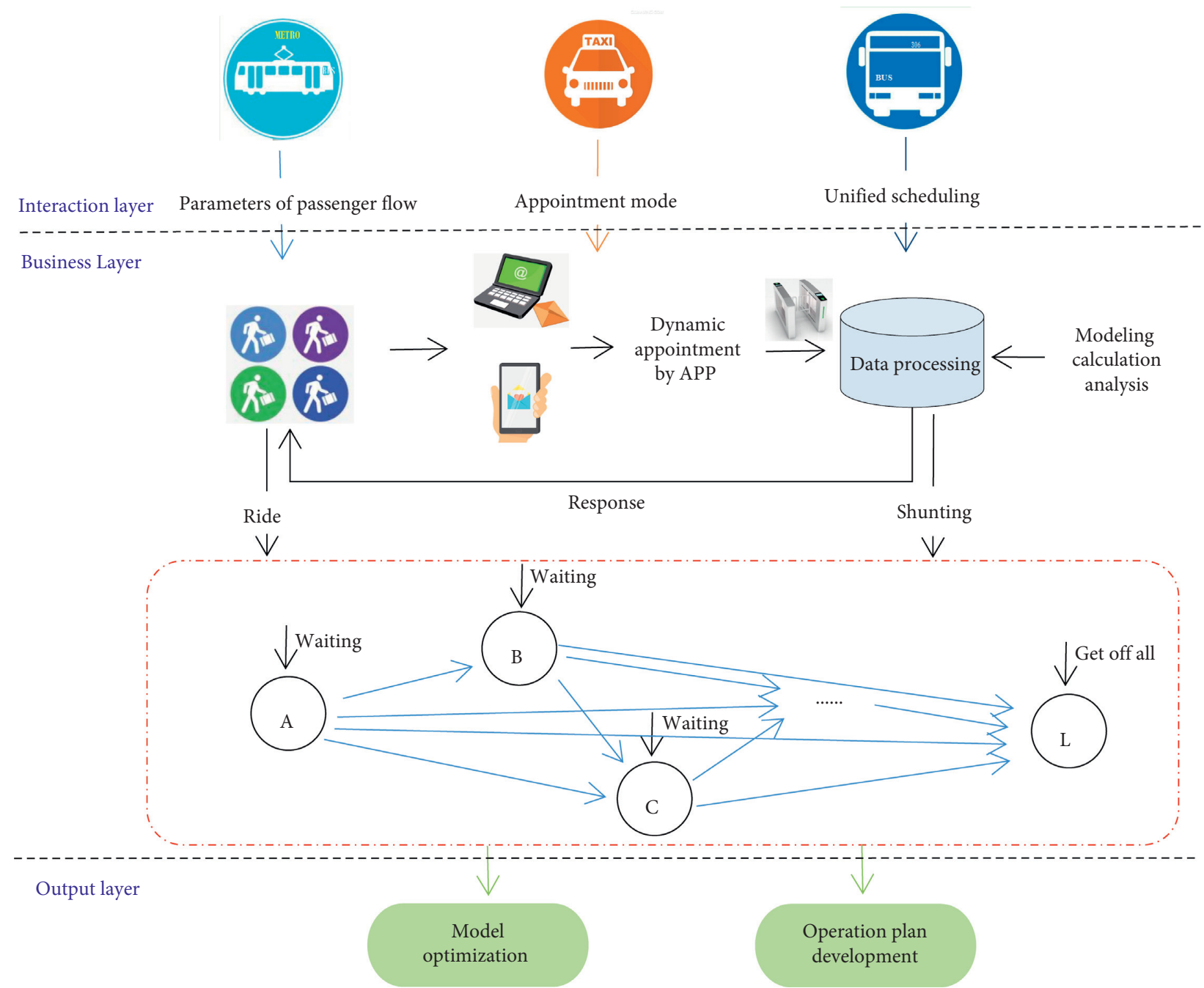

FIgURE 2: Dispatch system process and route conditions for customized bus.

(3) The lowest total cost is as follows:

$$
\min f=\min f_{1}+\min f_{2},
$$

s.t.

$$
\begin{gathered}
\sum_{i} x_{i j k}=\sum_{i} x_{j i k}, \quad \forall j \in S, \forall k \in T, \\
n_{i}^{p q}=\sum_{k} n_{i k}^{p q}, \quad \forall i \in S, \\
n_{i}^{p h}=\sum_{k} n_{i k}^{p h}, \quad \forall i \in S, \quad \forall i \in S, \\
0 \leq n_{i}^{p q} \leq \sum_{k} n_{i k}^{v} C_{k}-\sum_{j=1}^{i-1}\left(n_{j}^{p q}-n_{j}^{p h}\right)+n_{i}^{p h}, \quad \forall i \in S . \\
0 \leq n_{i}^{p h} \leq \sum_{j=1}^{i-1}\left(n_{j}^{p q}-n_{j}^{p h}\right), \quad \forall
\end{gathered}
$$

$$
\begin{gathered}
n_{i}^{g p} \leq Y_{i}^{g p}, \quad \forall i \in S, \\
n_{i}^{e p} \leq Y_{i}^{e p}, \quad \forall i \in S, \\
\sum_{i} \sum_{k} n_{i k}^{v} \leq N, \\
\sum_{l} \sum_{i} t_{l i}^{w}=\sum_{l} \sum_{i}\left(t_{l i}^{d}-t_{l i}^{a}\right) \times 60, \\
t_{l i}^{w} \leq T_{r}+T_{c}+T_{d}, \quad \forall l \in P, \forall i \in S .
\end{gathered}
$$

Among the constraints, Equation (4) indicates that the vehicle entering the station should leave; Equation (5) indicates the number of passengers getting on at each station; Equation (6) indicates the number of passengers getting off at each station; Equation (7) indicates the range of the number of passengers getting on at each station; Equation (8) indicates the range of the number of passengers getting off at each station; Equation (9) indicates the passenger flow range at ground stations; Equation (10) indicates the range of 
TABLe 1: Notation.

\begin{tabular}{|c|c|}
\hline Symbol & Definition and description \\
\hline \multicolumn{2}{|l|}{ Sets } \\
\hline$S$ & The set of stations \\
\hline$T$ & The set of vehicle types \\
\hline$P$ & The set of passengers \\
\hline \multicolumn{2}{|c|}{ Parameters } \\
\hline$i, j$ & Bus station, indexed as $i, j \in S$ \\
\hline$l$ & Passenger, indexed as $l \in P$ \\
\hline$k$ & Type of the vehicle $k$, indexed as $k \in T$ \\
\hline$N$ & Total number of vehicles \\
\hline$C_{k}$ & Capacity of the vehicle of type $k /$ person \\
\hline$d_{i j}$ & Travel distance from station $i$ to station $(j / m)$ \\
\hline$c_{k}^{f}$ & Fixed cost of the vehicle of type $k$ (yuan'vehicle ${ }^{-1}$ ) \\
\hline$c_{k}^{u}$ & Unit distance cost of the vehicle of type $k(y u a n / m)$ \\
\hline$c_{w}$ & The cost of waiting time (yuan/min) \\
\hline$n_{i k}^{p q}$ & The number of passengers getting on the vehicle of type $k$ at station $i$ \\
\hline$n_{i k}^{p h}$ & The number of passengers getting off the vehicle of type $k$ at station $i$ \\
\hline$n_{i}^{p q}$ & The number of passengers getting on at station $i$ \\
\hline$n_{i}^{p h}$ & The number of passengers getting off at station $i$ \\
\hline$n_{i}^{g p}$ & Passenger flow volume in ground station each hour \\
\hline$n_{i}^{e p}$ & Passenger flow volume in elevated station each hour \\
\hline$Y_{i}^{g p}$ & Passenger flow volume in ground station at peak hour \\
\hline$Y_{i}^{e p}$ & Passenger flow volume in elevated station at peak hour \\
\hline$t_{l i}^{d}$ & Appointment deadline set by the app $(h)$ \\
\hline$t_{l i}^{a l}$ & Arrival time of passenger $l$ at station $i(h)$ \\
\hline$t_{l i}^{w}$ & Waiting time of passenger $l$ at station $i$ (min) \\
\hline$T_{r}$ & Appointment time interval set by APP (min) \\
\hline$T_{c}$ & Iteration time of computer (min) \\
\hline$T_{d}$ & Time for dispatching vehicles and drivers ( $\mathrm{min}$ ) \\
\hline
\end{tabular}

Decision variables

$x_{i j k} x_{i j k}=1$

If a vehicle of type $k$ travels from station $i$ to station $j$ and $x_{i j k}=0$ otherwise $n_{i k}^{v}$ The number of vehicles of type $k$ dispatched at the station $i$

passenger flow at elevated stations; Equation (11) indicates the limit of the number of vehicles of all types at each station; Equation (12) indicates the waiting time of passengers at stations; and Equation (13) indicates the waiting time range of each passenger at each station.

\section{Genetic Algorithm Application}

To obtain the optimal solution for the model constructed by the customized bus dynamic dispatching system for Section 3 , it is necessary to select a suitable algorithm to solve the problem. Through literature research, the pros and cons of some methods are analyzed.

Wang et al. [36] used the simulated annealing algorithm to solve the vehicle routing problem with both pickup and delivery time windows. Kumar et al. [37] proposed an improved simulated annealing algorithm to simulate electric buses for Dehradun Smart City, which improves the calculation accuracy to a certain extent but still continues the shortcomings of the traditional simulated annealing algorithm that the global search ability is poor. Pessoa et al. [38] used an improved branch price cut algorithm to solve the problem of heterogeneous fleet vehicle routing in warehouse transportation. However, its convergence needs to be improved when solving the multiobjective complexity problem. Cheikh et al. [39] used a variable neighborhood search algorithm to study the variable multitrip vehicle routing problem, but the algorithm has low convergence in calculations. The mixed integer solver has certain advantages for solving the relaxation problem in multiobjective optimization [40], but it still has certain difficulties in obtaining the global optimal solution [41].

The genetic algorithm can solve multiobjective optimization problems combining the strong global search ability and implicit parallel search characteristics [42, 43]. It is a practical, efficient, and robust optimization technology, which is widely used in various fields [44-46]. For example, Marín Moreno et al. [47] used genetic algorithms to solve the reality of the Colombian transportation system (2 warehouses and 719 services) in warehouse cargo transportation, and the fleet size has been reduced. The study by Xiao and Konak [48] combined with the genetic algorithm solved the problem of green vehicle routing and scheduling in road transportation, which reduced carbon dioxide emissions and fuel consumption.

In this study, how to achieve the best matching of different vehicle combinations and multiple paths to optimize the target value is a difficult point in the solution. It can be 
solved through double coding and chromosome pairing in the genetic algorithm.

Therefore, this paper adopts the genetic algorithm natural number two-layer coding strategy to solve the vehicle scheduling model. The process of applying the genetic algorithm to the customized bus dynamic dispatching model of multiline hybrid vehicles is shown in Figure 3.

4.1. Double Coding. The first layer of coding: length $g=$ the number of all OD pairs, which means the OD pair belongs to the line number.

The second level of coding: length $h=$ all OD logarithms $\mathrm{K}^{*}$, which means the OD pair corresponds to the type number. If the gene is 0 , the type is not selected; otherwise, the type is selected.

For example, there are $g=4$ stations $(\mathrm{A} \sim \mathrm{D}), h=6 \mathrm{OD}$ pairs, 3 types, using double-layer coding. The green part is the first layer of coding, and the yellow part is the second layer of coding. The coding analysis is shown in Figure 4.

1,2 means the first OD pair from site A to site B.

1,3 means the second OD pair from site A to site C.

1,4 means the third OD pair from site A to site D.

2,3 means the fourth OD pair from site B to site C.

2,4 means the fifth OD pair from site B to site D.

3,4 means the sixth OD pair from site $C$ to site $D$.

Then, $S 1=[1,2 ; 1,3 ; 1,4]$ (the starting point of the OD pair is 1); it can be seen that the maximum number of OD pairs governed by $\mathrm{S} 1$ is 3 (because there are 3 elements); similarly, $S 2=[2,3 ; 2,4]$, the maximum number of OD pairs that can be numbered 2 ; and $S 3=[3,4]$, the maximum number of OD pairs that can be numbered 1 . Then, a legal chromosome can be expressed as $[3,3,3,2,2,1]$.

Its meaning is the first paragraph $[3,3,3]$ means that the three OD pairs of S1 are all numbered 3. Then, they need to be merged into one route; that is, the starting point is 1 (A), the halfway stop is $2(\mathrm{~B})$ and $3(\mathrm{C})$, and finally $4(D)$ is reached, so as to realize path 3 . The second segment $\mathrm{S} 2$ and the third segment S3 merge the route in the same way (note: the line numbers of OD pairs at different starting points are independent and do not interfere with each other).

\subsection{Variation and Crossover}

4.2.1. Single-Point Mutation. A natural number is generated by random mutation, as shown in Figure 5, where 1 changes to 5 .

4.2.2. Use Two-Point Crossover. Two chromosomes are randomly selected as the paternal parent, and the gene fragments are exchanged between the two paternal chromosomes to obtain two offspring chromosomes. As shown in Figure 6, $[8,0]$ in parent 1 and $[2,8]$ in parent 2 are exchanged.

4.2.3. Calculate the Objective Function. The objective function and constraints are calculated according to the set objective function, and the fitness function is expressed as follows:

$$
\begin{aligned}
F_{i} & =\frac{1}{y_{i}+P_{i}}, \\
y_{i} & =\min f(x) .
\end{aligned}
$$

Among them, $F_{i}$ is the fitness value of chromosome $i, y_{i}$ is the objective function of chromosome $i$, and $P_{i}$ is the penalty value of chromosome $i$.

4.3. Roulette Selection. Roulette selection is also called proportional selection operator. The basic idea is that the probability of an individual being selected is proportional to the value of its fitness function. Gene selection uses a roulette method, and the ratio of the fitness of each chromosome to the sum of the fitness of all chromosomes is used as the probability of being selected for the chromosome. Assuming that the population size is $n$ and the fitness of individual $i$ is $F_{i}$, the probability that individual $i$ will be selected and inherited to the next population is as follows:

$$
P_{i}=\frac{F_{i}}{\sum_{i=1}^{n} F_{i}}
$$

Suppose that the probability of each chromosome being selected is $P_{i}$ and $S_{i}$ is a number randomly generated by chromosome $i$, with a value between 0 and 1 . If $S_{i}<P_{i}$, chromosome $i$ is selected for the next operation.

\section{Simulation Analysis}

5.1. Case Analysis. Table 2 gives the input parameters of some constant variables, based on Table 1 .

Table 3 shows the distance matrix between stations. Table 4 shows the running time matrix between stations.

According to the maximum passenger flow during peak hours on ground platforms and elevated platforms, the data in the table refer to the peak hour passenger flow of ground platforms and elevated platforms. Assume that the passenger reservation time interval set by the APP is 10 minutes. For example, select 9:01-9:10 time period data. Table 5 is the dynamic statistics table of the number of reservations for each station during this period (passengers can cancel the reservation at any time between 9:01-9:10; all data processed and analyzed by APP at 9:10). Table 6 shows the number of passengers on/off at the last appointment time of each station (the number of passengers boarding at each station is equivalent to the number of passengers dropping off at other stations; for example, the total number of people getting on the bus at station $\mathrm{A}$ is equal to the total number of people getting off the bus, which is 587 people).

The data in Tables 5 and 6 are shown in Figure 7, respectively, to show the dynamic change effect about passenger flow on/off at each station at the time of APP processing. Among them, Figure 7 (a)indicates the dynamic reservation number $(9: 01-9: 10)$, and the module in the 


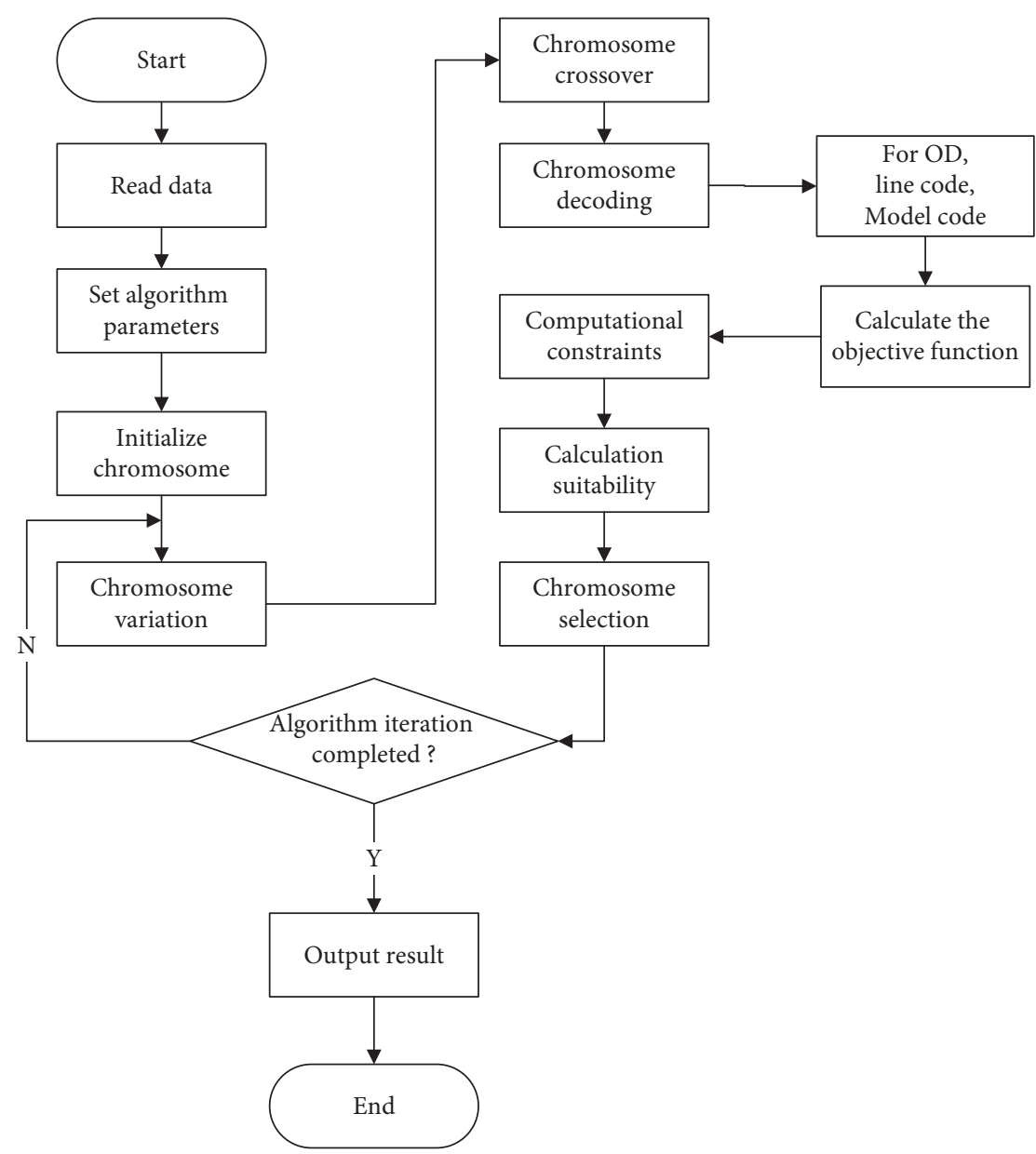

Figure 3: Genetic algorithm solving process.

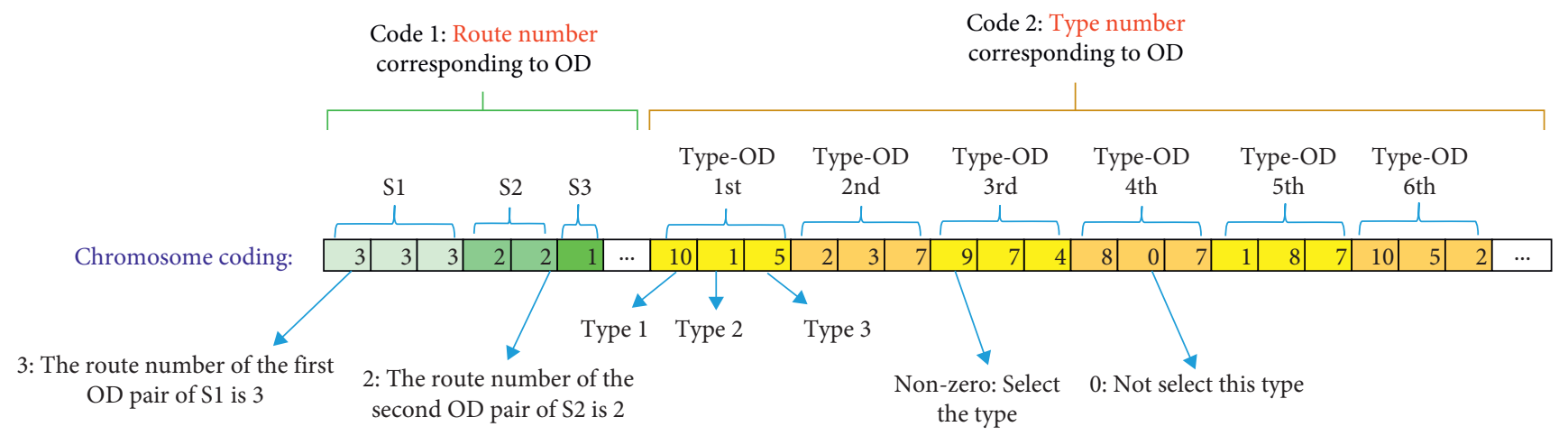

Figure 4: Double-layer coding analysis.

\begin{tabular}{|c|c|c|c|c|c|c|c|c|c|c|c|c|c|c|c|c|c|c|c|c|c|c|c|c|c|c|}
\hline Father generation & 3 & 3 & 3 & 2 & 2 & 1 & $\ldots$ & 10 & $1 \mid$ & 5 & $2 \mid$ & \begin{tabular}{l|l}
3 & \\
\end{tabular} & 7 & \begin{tabular}{l|l}
9 \\
\end{tabular} & 7 & 4 & 8 & \begin{tabular}{l|l}
0 & \\
\end{tabular} & 7 & 1 & \begin{tabular}{l|l}
8 & \\
\end{tabular} & 7 & 10 & \begin{tabular}{l|l}
5 \\
\end{tabular} & 2 & $\ldots$ \\
\hline Mutant offspring & 3 & 3 & 3 & 2 & 2 & 1 & $\ldots$ & 10 & $1 \mid$ & 5 & \begin{tabular}{l|l}
2 & \\
\end{tabular} & \begin{tabular}{l|l}
3 & \\
\end{tabular} & $7 \mid$ & $9 \mid$ & 7 & $4 \mid$ & 8 & \begin{tabular}{l|l}
0 & \\
\end{tabular} & 7 & 5 & \begin{tabular}{|l|l}
8 & \\
\end{tabular} & 7 & 10 & 5 & 2 & $\ldots$ \\
\hline
\end{tabular}

FIGURE 5: Variant structure. 


\begin{tabular}{|c|c|c|c|c|c|c|c|c|c|c|c|c|c|c|c|c|c|c|c|c|c|c|c|c|}
\hline Paternal Chromosome 1 & 3 & 3 & 3 & 1 & 1 & 1 & $\ldots$ & 10 & 1 & 5 & 2 & 3 & 7 & \begin{tabular}{l|l}
9 \\
\end{tabular} & 7 & \begin{tabular}{l|l|}
4 & 8 \\
\end{tabular} & \begin{tabular}{l|l|}
0 & 7 \\
\end{tabular} & 5 & 8 & 7 & 10 & 5 & 2 & $\ldots$ \\
\hline Paternal Chromosome 2 & 3 & 3 & 1 & 1 & 2 & 1 & $\ldots$ & 9 & 5 & 8 & 8 & 8 & 5 & \begin{tabular}{l|l}
4 \\
\end{tabular} & 4 & 21 & $8 \longdiv { 1 }$ & \begin{tabular}{l|l}
0 \\
\end{tabular} & \begin{tabular}{l|l}
0 \\
\end{tabular} & 6 & 0 & $8 \mid$ & 8 & $\ldots$ \\
\hline Cross offspring 1 & 3 & 3 & 3 & 1 & 1 & 1 & $\ldots$ & 10 & 5 & 8 & 8 & 8 & 5 & 4 & 4 & 28 & 1 & 0 & 8 & 7 & 10 & 5 & 2 & $\ldots$ \\
\hline Cross offspring 1 & 3 & 3 & 1 & 1 & 2 & 1 & $\ldots$ & 9 & 1 & 8 & 2 & 8 & 7 & 9 & 7 & $4 \triangle 8$ & $0 \longdiv { 7 }$ & 5 & 0 & 6 & 0 & 8 & 8 & 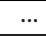 \\
\hline
\end{tabular}

Figure 6: Crossover structure.

TABLE 2: Constant variables in the calculation example.

Variable name Variable

Number of stations 12

Length of the maximum line $(\mathrm{km})$ 15

Speed of vehicle $\left(\mathrm{km} \cdot \mathrm{h}^{-1}\right)$

Total number of vehicles

Passenger flow volume in ground station at peak hour

Passenger flow volume in elevated station at peak hour

Capacity of the vehicle $C_{1}$ /person

Capacity of the vehicle $C_{2} /$ person

Capacity of the vehicle $C_{3} /$ person

Fixed cost $c_{1}^{f}$ (yuan.vehicle ${ }^{-1}$ )

Fixed cost $c_{2}^{f}$ (yuan.vehicle ${ }^{-1}$ )

Fixed cost $c_{3}^{f}$ (yuan.vehicle ${ }^{-1}$ )

Unit driving cost $c_{2}^{u}$ (yuan/m)

TABle 3: The distance matrix between stations ( $\mathrm{m}$ ).

\begin{tabular}{lcccccccccccc}
\hline Site & A & B & C & D & E & F & G & H & I & J & K \\
\hline A & - & 1100 & 2300 & 3850 & 5300 & 6500 & 8150 & 10000 & 11200 & 12500 & 13800 & 15000 \\
B & - & - & 1400 & 2800 & 4350 & 5600 & 7100 & 8900 & 10200 & 11400 & 12750 & 13900 \\
C & - & - & - & 1500 & 2950 & 4200 & 5800 & 7500 & 8800 & 10000 & 11350 & 12500 \\
D & - & - & - & - & 1450 & 2700 & 4300 & 6000 & 7300 & 8500 & 9850 & 11000 \\
E & - & - & - & - & - & 1250 & 2850 & 4550 & 5800 & 7050 & 8400 & 9550 \\
F & - & - & - & - & - & - & 1600 & 3300 & 4600 & 5800 & 7150 & 8300 \\
G & - & - & - & - & - & - & - & 1700 & 3000 & 4200 & 5550 & 6700 \\
H & - & - & - & - & - & - & - & - & 1300 & 2500 & 3850 & 5000 \\
I & - & - & - & - & - & - & - & - & - & 1200 & 2550 & 3700 \\
J & - & - & - & - & - & - & - & - & - & - & 1350 & 2500 \\
K & - & - & - & - & - & - & - & - & - & - & - & 1150 \\
L & - & - & - & - & - & - & - & - & - & - & - \\
\hline
\end{tabular}

TABLE 4: Running time matrix between stations (min).

\begin{tabular}{|c|c|c|c|c|c|c|c|c|c|c|c|c|}
\hline Site & A & $\mathrm{B}$ & $\mathrm{C}$ & $\mathrm{D}$ & $\mathrm{E}$ & $\mathrm{F}$ & G & $\mathrm{H}$ & I & $\mathrm{J}$ & $\mathrm{K}$ & $\mathrm{L}$ \\
\hline $\mathrm{A}$ & - & 0.9 & 1.9 & 3.2 & 4.4 & 5.4 & 6.8 & 8.3 & 9.3 & 10.4 & 11.5 & 12.5 \\
\hline B & - & - & 1.2 & 2.3 & 3.6 & 4.7 & 5.9 & 7.4 & 8.5 & 9.5 & 10.6 & 11.6 \\
\hline $\mathrm{C}$ & - & - & - & 1.3 & 2.5 & 3.5 & 4.8 & 6.3 & 7.3 & 8.3 & 9.5 & 10.4 \\
\hline $\mathrm{D}$ & - & - & - & - & 1.2 & 2.3 & 3.6 & 5 & 6.1 & 7.1 & 8.2 & 9.2 \\
\hline $\mathrm{E}$ & - & - & - & - & - & 1 & 2.4 & 3.8 & 4.8 & 5.9 & 7 & 8 \\
\hline $\mathrm{F}$ & - & - & - & - & - & - & 1.3 & 2.8 & 3.8 & 4.8 & 6 & 6.9 \\
\hline G & - & - & - & - & - & - & - & 1.4 & 2.5 & 3.5 & 4.6 & 5.6 \\
\hline $\mathrm{H}$ & - & - & - & - & - & - & - & - & 1.1 & 2.1 & 3.2 & 4.2 \\
\hline I & - & - & - & - & - & - & - & - & - & 1 & 2.1 & 3.1 \\
\hline $\mathrm{J}$ & - & - & - & - & - & - & - & - & - & - & 1.1 & 2.1 \\
\hline $\mathrm{K}$ & - & - & - & - & - & - & - & - & - & - & - & 1 \\
\hline $\mathrm{L}$ & - & - & - & - & - & - & - & - & - & - & - & - \\
\hline
\end{tabular}


TABLE 5: Dynamic statistics of the number of reservations on each station.

\begin{tabular}{|c|c|c|c|c|c|c|}
\hline Site & $9: 01$ & $9: 02$ & $9: 04$ & $9: 06$ & $9: 08$ & $9: 10$ \\
\hline A & 320 & 460 & 575 & 580 & 590 & 587 \\
\hline B & 130 & 340 & 530 & 520 & 537 & 522 \\
\hline $\mathrm{C}$ & 150 & 200 & 290 & 480 & 520 & 499 \\
\hline $\mathrm{D}$ & 100 & 240 & 350 & 380 & 420 & 413 \\
\hline $\mathrm{E}$ & 130 & 260 & 300 & 360 & 405 & 381 \\
\hline $\mathrm{F}$ & 210 & 235 & 310 & 350 & 380 & 359 \\
\hline G & 120 & 156 & 180 & 230 & 263 & 283 \\
\hline $\mathrm{H}$ & 67 & 130 & 210 & 270 & 280 & 279 \\
\hline I & 19 & 79 & 150 & 160 & 230 & 225 \\
\hline $\mathrm{J}$ & 20 & 130 & 150 & 160 & 163 & 159 \\
\hline K & 24 & 19 & 37 & 58 & 80 & 94 \\
\hline $\mathrm{L}$ & & & & & - & - \\
\hline
\end{tabular}

TABle 6: Passenger drop-off matrix between stations.

\begin{tabular}{llllllllllllll}
\hline Site & A & B & C & D & E & F & G & H & I & J & K & L & Total \\
\hline A & - & 64 & 58 & 53 & 41 & 56 & 74 & 43 & 51 & 67 & 45 & 35 \\
B & - & - & 51 & 54 & 67 & 42 & 39 & 67 & 50 & 68 & 45 & 39 & 522 \\
C & - & - & - & 58 & 63 & 45 & 60 & 47 & 56 & 59 & 65 & 46 & 499 \\
D & - & - & - & - & 57 & 63 & 50 & 46 & 63 & 45 & 36 & 53 & 413 \\
E & - & - & - & - & - & 56 & 64 & 71 & 45 & 52 & 36 & 57 & 381 \\
F & - & - & - & - & - & - & 53 & 65 & 76 & 45 & 56 & 64 & 359 \\
G & - & - & - & - & - & - & - & 55 & 67 & 30 & 67 & 64 & 283 \\
H & - & - & - & - & - & - & - & - & 67 & 84 & 55 & 73 & 279 \\
I & - & - & - & - & - & - & - & - & - & 83 & 75 & 67 & 225 \\
J & - & - & - & - & - & - & - & - & - & - & 83 & 76 & 159 \\
K & - & - & - & - & - & - & - & - & - & - & - & 94 & 94 \\
L & - & - & - & - & - & - & - & - & - & - & - & - & - \\
\hline
\end{tabular}

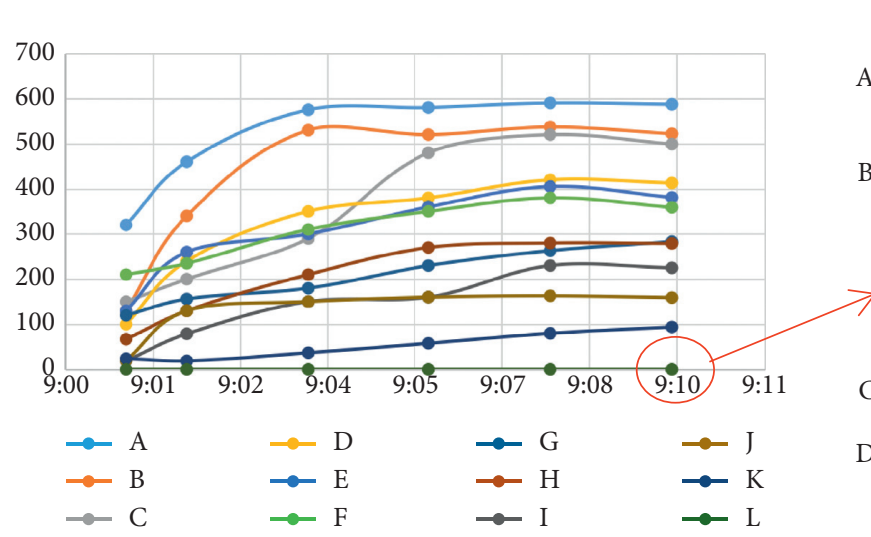

(a)

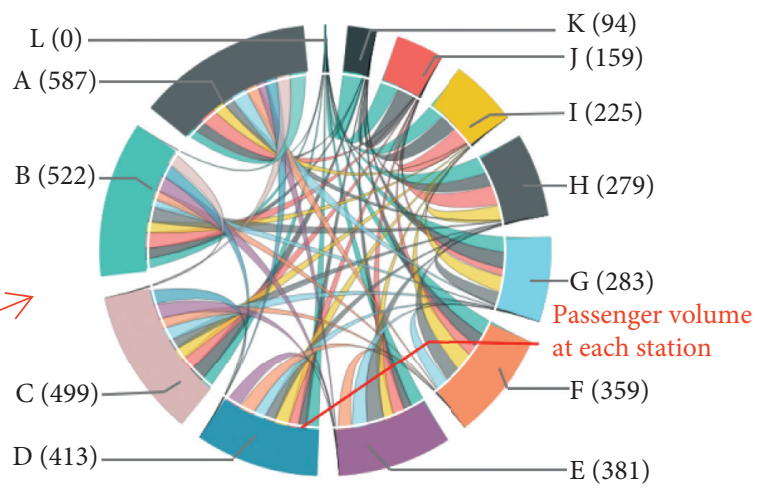

(b)

FIGURE 7: Passenger flow on/off at each station at the time of APP processing: (a) dynamic reservation number (9:01-9:10); (b) number of appointments by deadline $(9: 10)$.

white circle area in Figure 7(b) shows the number of passengers dropping off from each station to other stations at the deadline $(9: 10)$.

According to Tables 5 and 6, the passenger flow of each station of the APP processing node can be obtained. Swipe the card data from the gate to obtain information such as the number of people arriving at the site within the scheduled time period, time node, and so on (note: the number of arrivals at different times is not cumulative). Set the total computer dispatch response time (from receiving data to dispatching the bus) as 5 minutes. After the computer calculates the reservation data, the passenger waiting information for the gate ticket inspection at the last reservation time node $(9: 10)$ of each station is obtained in Table 7 . Assume that all reserved passengers leave the station.

5.2. Program of Vehicle Driving. The genetic algorithm is used to calculate based on the data analysis of 4.1. In this example, there are 12 stations, 66 OD pairs, and 3 vehicle 
TABLE 7: Passenger waiting information statistics table at the last time node of each station.

\begin{tabular}{|c|c|c|c|c|}
\hline Site & Total number of people on the bus & Number of people arriving at the station at each time & Arriving time $(\mathrm{h})$ & Waiting time (min) \\
\hline \multirow{10}{*}{ A } & \multirow{10}{*}{587} & 70 & $9: 01$ & 14 \\
\hline & & 85 & $9: 02$ & 13 \\
\hline & & 45 & $9: 03$ & 12 \\
\hline & & 67 & $9: 04$ & 11 \\
\hline & & 30 & $9: 05$ & 10 \\
\hline & & 24 & $9: 06$ & 9 \\
\hline & & 35 & $9: 07$ & 8 \\
\hline & & 60 & $9: 08$ & 7 \\
\hline & & 45 & $9: 09$ & 6 \\
\hline & & 126 & $9: 10$ & 5 \\
\hline$\vdots$ & $\vdots$ & $\vdots$ & $\vdots$ & $\vdots$ \\
\hline \multirow{10}{*}{ K } & \multirow{10}{*}{94} & 5 & $9: 01$ & 14 \\
\hline & & 6 & $9: 02$ & 13 \\
\hline & & 9 & $9: 03$ & 12 \\
\hline & & 12 & $9: 04$ & 11 \\
\hline & & 25 & $9: 05$ & 10 \\
\hline & & 6 & $9: 06$ & 9 \\
\hline & & 17 & $9: 07$ & 8 \\
\hline & & 5 & $9: 08$ & 7 \\
\hline & & 2 & $9: 09$ & 6 \\
\hline & & 7 & $9: 10$ & 5 \\
\hline $\mathrm{L}$ & - & - & - & - \\
\hline
\end{tabular}

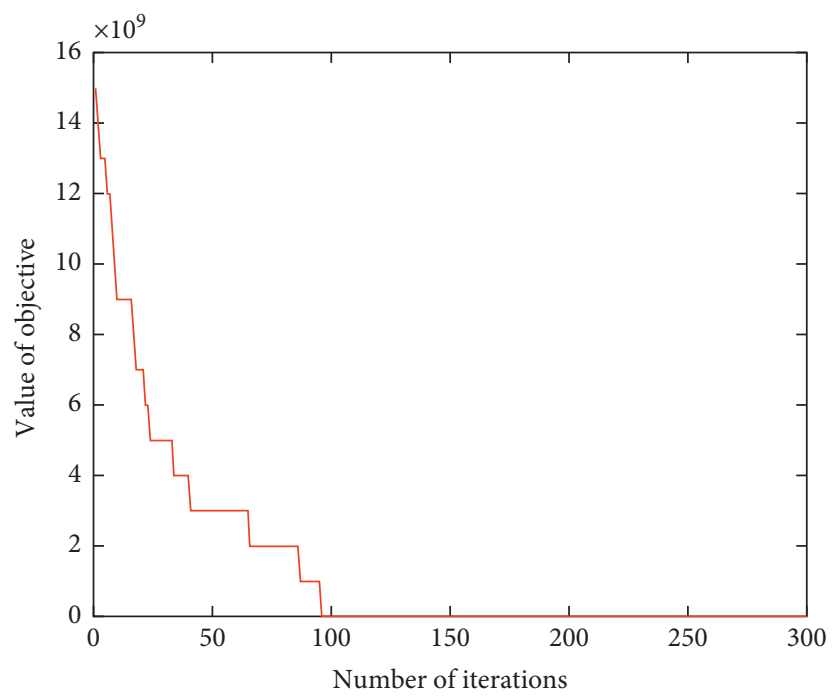

FIGURE 8: The optimal value iteration curve.

types. A computer with a processor Intel-Core (i7) and a memory of $16 \mathrm{G}$ is chosen, and MATLAB is used for programming. The genetic algorithm population size is set to 200 , the maximum number of iterations is 300 , the mutation probability coefficient is 0.1 , and the crossover probability coefficient is 0.7 . The algorithm terminates when the suitability of the optimal individual and the suitability of the group no longer change. The iteration curve calculated by the genetic algorithm is shown in Figure 8 (iteration time $1 \mathrm{~min} 5 \mathrm{~s}$ ).

Since the APP sets the appointment time period as 10 minutes and the computer iteration time is $1 \mathrm{~min} 5 \mathrm{~s}$, the rationality of the appointment time interval set by APP can be verified by (13). Calculated by the genetic algorithm, the output results are listed in Table 8 .

Result Description. 66 routes can be formed randomly from the starting station A to the end station $L$, and each route is composed of three vehicle types. Among them, bus types 1,2 , and 3, respectively, represent 5-seater, 11-seater, and 22-seater (the system is set to give priority to the use of large vehicles). In the driving path, 1 means stop and 0 means no stop (except for the starting and ending points, intermediate station does not stop). The same route number indicates the combination of vehicle types. For example, 
TABLE 8: Output result information table.

\begin{tabular}{|c|c|c|c|c|c|c|c|}
\hline $\begin{array}{l}\text { Line } \\
\text { number }\end{array}$ & Types & $\begin{array}{c}\text { Number of } \\
\text { vehicles }\end{array}$ & Driving path & $\begin{array}{l}\text { Corresponding } \\
\text { track }\end{array}$ & $\begin{array}{l}\text { Mileage } \\
(\mathrm{km})\end{array}$ & $\begin{array}{c}\text { The operating cost of } \\
\text { enterprise (yuan) }\end{array}$ & $\begin{array}{c}\text { Total cost } \\
\text { (yuan) }\end{array}$ \\
\hline 1 & 3 & 2 & $1,0,0,0,0,0,0,0,1,0,0,0$ & A-I & 11.2 & 1440 & \multirow{28}{*}{18151.44} \\
\hline 1 & 1 & 2 & $1,0,0,0,0,0,0,0,1,0,0,0$ & A-I & 11.2 & 503.2 & \\
\hline 2 & 3 & 1 & $1,0,0,0,1,0,0,0,0,0,0,0$ & $A-E$ & 5.3 & 425 & \\
\hline 2 & 2 & 1 & $1,0,0,0,1,0,0,0,0,0,0,0$ & A-E & 5.3 & 264.9 & \\
\hline 2 & 1 & 2 & $1,0,0,0,1,0,0,0,0,0,0,0$ & A-E & 5.3 & 290.8 & \\
\hline 3 & 3 & 2 & $1,0,0,1,0,0,0,0,0,0,0,0$ & A-D & 3.85 & 705 & \\
\hline 3 & 1 & 2 & $1,0,0,1,0,0,0,0,0,0,0,0$ & A-D & 3.85 & 238.6 & \\
\hline 4 & 3 & 2 & $1,0,0,0,0,0,0,0,0,0,1,0$ & $A-K$ & 13.8 & 1700 & \\
\hline 4 & 1 & 1 & $1,0,0,0,0,0,0,0,0,0,1,0$ & $A-K$ & 13.8 & 298.4 & \\
\hline 5 & 3 & 2 & $1,1,0,0,0,0,0,0,0,0,0,0$ & A-B & 1.1 & 430 & \\
\hline 5 & 2 & 1 & $1,1,0,0,0,0,0,0,0,0,0,0$ & $A-B$ & 1.1 & 126.3 & \\
\hline 5 & 1 & 2 & $1,1,0,0,0,0,0,0,0,0,0,0$ & $A-B$ & 1.1 & 139.6 & \\
\hline 6 & 3 & 3 & $1,0,0,0,0,0,0,0,0,1,0,0$ & A-J & 12.5 & 2355 & \\
\hline 6 & 1 & 1 & $1,0,0,0,0,0,0,0,0,1,0,0$ & A-J & 12.5 & 275 & \\
\hline 7 & 3 & 1 & $1,0,0,0,0,0,0,0,0,0,0,1$ & A-L & 15 & 910 & \\
\hline 7 & 2 & 1 & $1,0,0,0,0,0,0,0,0,0,0,1$ & A-L & 15 & 585 & \\
\hline 7 & 1 & 1 & $1,0,0,0,0,0,0,0,0,0,0,1$ & A-L & 15 & 320 & \\
\hline 8 & 3 & 2 & $1,0,0,0,0,1,0,0,0,0,0,0$ & A-F & 6.5 & 970 & \\
\hline 8 & 2 & 1 & $1,0,0,0,0,1,0,0,0,0,0,0$ & A-F & 6.5 & 304.5 & \\
\hline 8 & 1 & 1 & $1,0,0,0,0,1,0,0,0,0,0,0$ & A-F & 6.5 & 167 & \\
\hline 9 & 3 & 2 & $1,0,1,0,0,0,0,0,0,0,0,0$ & $\mathrm{~A}-\mathrm{C}$ & 2.3 & 550 & \\
\hline 9 & 2 & 1 & $1,0,1,0,0,0,0,0,0,0,0,0$ & $\mathrm{~A}-\mathrm{C}$ & 2.3 & 165.9 & \\
\hline 9 & 1 & 1 & $1,0,1,0,0,0,0,0,0,0,0,0$ & $\mathrm{~A}-\mathrm{C}$ & 2.3 & 91.4 & \\
\hline 10 & 3 & 3 & $1,0,0,0,0,0,1,0,0,0,0,0$ & $A-G$ & 8.15 & 1702.5 & \\
\hline 10 & 1 & 2 & $1,0,0,0,0,0,1,0,0,0,0,0$ & $A-G$ & 8.15 & 393.4 & \\
\hline 11 & 3 & 1 & $1,0,0,0,0,0,0,1,0,0,0,0$ & A-H & 10 & 660 & \\
\hline 11 & 2 & 1 & $1,0,0,0,0,0,0,1,0,0,0,0$ & A-H & 10 & 420 & \\
\hline 11 & 1 & 2 & $1,0,0,0,0,0,0,1,0,0,0,0$ & A-H & 10 & 460 & \\
\hline$\vdots$ & $\vdots$ & $\vdots$ & $\vdots$ & $\vdots$ & $\vdots$ & $\vdots$ & $\vdots$ \\
\hline 66 & 3 & 4 & $0,0,0,0,0,0,0,0,0,0,1,1$ & K-L & 1.15 & 870 & \multirow{2}{*}{1220.7} \\
\hline 66 & 1 & 2 & $0,0,0,0,0,0,0,0,0,0,1,1$ & K-L & 1.15 & 141.4 & \\
\hline
\end{tabular}

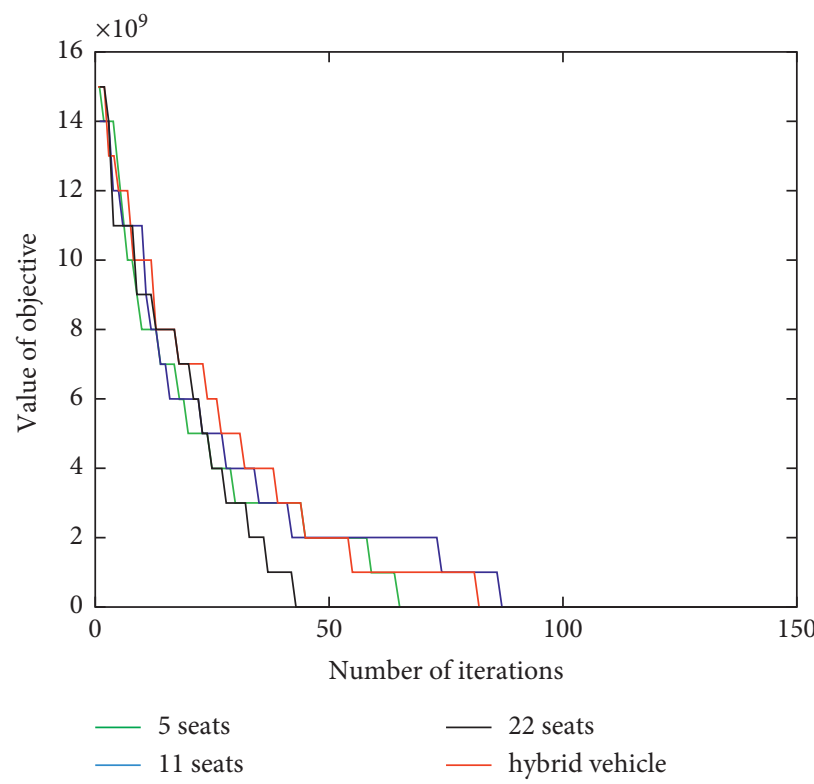

FIgURE 9: Comparison of iterative curves between hybrid types and single type. 
TABle 9: Comparison of hybrid vehicle and single-type solutions.

\begin{tabular}{lccccc}
\hline Program & Types & Driving path & Number of vehicles & Total cost (yuan) & Optimal fitness value \\
\hline Hybrid vehicle & 51122 & A-L & 271 & 95371.21 & $1.04853 \mathrm{E}-05$ \\
Single type & 5 & A-L & 786 & 128039.41 & $7.8101 \mathrm{E}-06$ \\
Single type & 11 & A-L & 380 & 114795.61 & $8.71113 \mathrm{E}-06$ \\
Single type & 22 & A-L & 208 & 101800.41 & $9.82314 \mathrm{E}-06$ \\
\hline
\end{tabular}

Route 1 consists of 2 buses with 22-seater and 2 buses with 5 seater. The driving track is A-I, the mileage is $11.2 \mathrm{~km}$, and the company's operating cost is 1943.2 yuan. The waiting cost at station A is 1259.94 yuan, and the total cost of getting on the bus at station $\mathrm{A}$ is 18151.44 yuan (note: the output data change with the dynamic changes of the input data.)

5.3. Program Comparison. On the basis of the flexible dynamic scheduling scheme of three vehicle types used in 4.2, the same parameters are set and compared with the single type scheme; the iteration curve is shown in Figure 9. The iteration times of the four curves of green, blue, black, and red (5-seater, 11-seater, 22-seater, and hybrid vehicle) from top to bottom are $1 \mathrm{~min} 1 \mathrm{~s}, 1 \mathrm{~min}, 58 \mathrm{~s}$, and $1 \mathrm{~min} 5 \mathrm{~s}$. It can be seen that the 22-seater type takes the least time, and the hybrid vehicle takes a relatively long time.

The number of vehicles allocated, total cost, and optimal applicability of the four options are compared, as listed in Table 9. It can be obtained from the table that the optimal applicability of the hybrid vehicle is the largest, its total cost is the lowest, and the number of vehicles allocated meets constraint (11). Neither 5-seater nor 11-seater types meet the requirements. Although the 22-seater type meets the requirements, it is likely to cause a low full load rate. The iteration time of hybrid vehicle is relatively long but within an acceptable range. With comprehensive consideration, the hybrid vehicle scheme is the most economical and reasonable.

\section{Conclusion}

In order to increase the attractiveness of public transportation and improve the service quality of public transportation enterprises, the dynamic dispatch model of multiline hybrid vehicles is investigated. The contributions of this study are summarized as follows.

First of all, the customized bus dispatch system in this study can meet the point-to-point service of multiple lines in the city center during peak hours. It combines the characteristics of taxis and subways to provide passengers with punctual, fast, and low-cost travel services.

Secondly, this study uses a hybrid vehicle and compares it with a single vehicle in terms of vehicle allocation, total cost, iteration time, and optimal applicability values. Through quantitative analysis, it is proved that the hybrid scheme is optimal.

Furthermore, the dynamic reservation period is set in the calculation example, and the rationality of the appointment time interval set by APP has been analyzed and verified. It can lay a theoretical foundation for making a reasonable dispatch plan based on passenger flow density.
To match it, some adjustments should be made in management. For example, based on the large number of vehicles, different types of vehicles and seats should be numbered to facilitate vehicle deployment and management. At the same time, the government should increase reasonable fare preferential policies to increase the attractiveness of the new method. Furthermore, the management department should provide appropriate stations to facilitate the shift and rest of the drivers.

In short, the research results show that the model can better reflect the actual bus dispatching situation. The disadvantage is that this study is mainly for one-way operation, and the return journey will be further integrated into the dispatch operation plan in the future.

\section{Data Availability}

The data used to support the findings of this study are included within the article, and the program code in the study is available upon request.

\section{Conflicts of Interest}

The authors declare that there are no conflicts of interest regarding the publication of this paper.

\section{Acknowledgments}

This work of the first author Xuemei Zhou was supported by National Natural Science Foundation of China (61873190) and National Railway Administration of the People's Republic of China (KF2019-007-B and KF2019-002-B) and the fourth author Xiangfeng Ji was supported by National Natural Science Foundation of China (71801138) and the Project funded by China Postdoctoral Science Foundation (2018M630744).

\section{References}

[1] B. K. Panigrahi, V. R. Pandi, S. Das, and S. Das, "Multiobjective fuzzy dominance based bacterial foraging algorithm to solve economic emission dispatch problem," Energy, vol. 35, no. 12, pp. 4761-4770, 2010.

[2] K. Sivakumaran, Y. Li, M. J. Cassidy, and S. Madanat, "Costsaving properties of schedule coordination in a simple trunkand-feeder transit system," Transportation Research Part A: Policy and Practice, vol. 46, no. 1, pp. 131-139, 2012.

[3] İ. Ö. Verbas and H. S. Mahmassani, "Exploring trade-offs in frequency allocation in a transit network using bus route patterns: methodology and application to large-scale urban systems," Transportation Research Part B: Methodological, vol. 81, pp. 577-595, 2015. 
[4] S. C. Wirasinghe and U. Vandebona, "Route layout analysis for express buses," Transportation Research Part C: Emerging Technologies, vol. 19, no. 2, pp. 374-385, 2011.

[5] T. Umlauf, L. D. Galicia, R. L. Cheu, and T. Horak, "Ridership estimation procedure for a transit corridor with new bus rapid transit service," Journal of Advanced Transportation, vol. 50, no. 4, pp. 473-488, 2016.

[6] J. Hatzenbühler, O. Cats, and E. Jenelius, "Transitioning towards the deployment of line-based autonomous buses: consequences for service frequency and vehicle capacity," Transportation Research Part A: Policy and Practice, vol. 138, pp. 491-507, 2020.

[7] S. Groth, "Multimodal divide: reproduction of transport poverty in smart mobility trends," Transportation Research Part A: Policy and Practice, vol. 125, pp. 56-71, 2019.

[8] J. Ma, M. Xu, Q. Meng, and L. Cheng, "Ridesharing user equilibrium problem under OD-based surge pricing strategy," Transportation Research Part B: Methodological, vol. 134, pp. 1-24, 2020.

[9] K. Liu, J. Zhang, and Q. Yang, "Bus pooling: a large-scale bus ridesharing service," IEEE Access, vol. 7, Article ID 74248, 2019.

[10] N. S. Caros and J. Y. J. Chow, “Day-to-day market evaluation of modular autonomous vehicle fleet operations with en-route transfers," Transportation Business: Transport Dynamics, vol. 9, no. 1, pp. 109-133, 2020.

[11] Z. Zhang, A. Tafreshian, and N. Masoud, "Modular transit: using autonomy and modularity to improve performance in public transportation," Transportation Research Part E: Logistics and Transportation Review, vol. 141, Article ID 102033, 2020.

[12] T. Liu, A. Ceder, and A. Rau, "Using deficit function to determine the minimum fleet size of an autonomous modular public transit system," Transportation Research Record: Journal of the Transportation Research Board, vol. 2674, no. 11, pp. 532-541, 2020.

[13] M. Pei, P. Lin, J. Du, X. Li, and Z. Chen, "Vehicle dispatching in modular transit networks: a mixed-integer nonlinear programming model," Transportation Research Part E: Logistics and Transportation Review, vol. 147, Article ID 102240, 2021.

[14] X. Liu, X. Qu, and X. Ma, "Improving flex-route transit services with modular autonomous vehicles," Transportation Research Part E: Logistics and Transportation Review, vol. 149, Article ID 102331, 2021.

[15] M. Gong, Y. Hu, Z. Chen, and X. Li, "Transfer-based customized modular bus system design with passenger-route assignment optimization," Transportation Research Part E: Logistics and Transportation Review, vol. 153, Article ID 102422, 2021.

[16] Q.-W. Guo, J. Y. J. Chow, and P. Schonfeld, "Stochastic dynamic switching in fixed and flexible transit services as market entry-exit real options," Transportation Research Part C: Emerging Technologies, vol. 94, pp. 288-306, 2018.

[17] Z. Chen, X. Li, and X. Zhou, "Operational design for shuttle systems with modular vehicles under oversaturated traffic: continuous modeling method," Transportation Research Part B: Methodological, vol. 132, pp. 76-100, 2020.

[18] S. M. Nourbakhsh and Y. Ouyang, "A structured flexible transit system for low demand areas," Transportation Research Part B: Methodological, vol. 46, no. 1, pp. 204-216, 2012.

[19] F. Qiu, W. Li, and J. Zhang, "A dynamic station strategy to improve the performance of flex-route transit services,"
Transportation Research Part C: Emerging Technologies, vol. 48, pp. 229-240, 2014.

[20] A. Neven, K. Braekers, K. Declercq, G. Wets, D. Janssens, and T. Bellemans, "Assessing the impact of different policy decisions on the resource requirements of a Demand Responsive Transport system for persons with disabilities," Transport Policy, vol. 44, pp. 48-57, 2015.

[21] L. dell'Olio, A. Ibeas, and F. Ruisánchez, "Optimizing bus-size and headway in transit networks," Transportation, vol. 39, no. 2, pp. 449-464, 2011.

[22] G.-J. Zhou, D.-F. Xie, X.-M. Zhao, and C. Lu, "Collaborative optimization of vehicle and charging scheduling for a bus fleet mixed with electric and traditional buses," IEEE Access, vol. 8, pp. 8056-8072, 2020.

[23] D. Sun, Y. Xu, and Z.-R. Peng, "Timetable optimization for single bus line based on hybrid vehicle size model," Journal of Traffic and Transportation Engineering, vol. 2, no. 3, pp. 179-186, 2015.

[24] E. Yao, T. Liu, T. Lu, and Y. Yang, "Optimization of electric vehicle scheduling with multiple vehicle types in public transport," Sustainable Cities and Society, vol. 52, Article ID 101862, 2020.

[25] L. Li, H. K. Lo, and F. Xiao, "Mixed bus fleet scheduling under range and refueling constraints," Transportation Research Part C: Emerging Technologies, vol. 104, pp. 443-462, 2019.

[26] S. Hassold and A. Ceder, "Public transport vehicle scheduling featuring multiple vehicle types," Transportation Research Part B: Methodological, vol. 67, pp. 129-143, 2014.

[27] W. A. Ellegood, J. F. Campbell, and J. North, "Continuous approximation models for mixed load school bus routing," Transportation Research Part B: Methodological, vol. 77, pp. 182-198, 2015.

[28] J. Wang, Z. Yuan, and Y. Yin, "Optimization of bus bridging service under unexpected metro disruptions with dynamic passenger flows," Journal of Advanced Transportation, vol. 2019, Article ID 6965728, 13 pages, 2019.

[29] S.-L. Zhang, Z.-Z. Yuan, and Z.-C. Cao, "Optimization model of bus operation plan based on hybrid bus sizes with constraints on vehicle capacity," Journal of Transportation Systems Engineering and Information Technology, vol. 7, no. 1, pp. 150-156, 2017.

[30] X. Lu, J. Yu, X. Yang, S. Pan, and N. Zou, "Flexible feeder transit route design to enhance service accessibility in urban area," Journal of Advanced Transportation, vol. 50, no. 4, pp. 507-521, 2016.

[31] L. Liu, L. Sun, Y. Chen, and X. Ma, "Optimizing fleet size and scheduling of feeder transit services considering the influence of bike-sharing systems," Journal of Cleaner Production, vol. 236, Article ID 117550, 2019.

[32] A. Charisis, C. Iliopoulou, and K. Kepaptsoglou, "DRT route design for the first/last mile problem: model and application to Athens, Greece," Public Transport, vol. 10, no. 3, pp. 499-527, 2018.

[33] H. Wang, "Routing and scheduling for a last-mile transportation system," Transportation Science, vol. 53, no. 1, pp. 131-147, 2019.

[34] H. Wang, L. Li, P. Pan, Y. Wang, and Y. Jin, "Early warning of burst passenger flow in public transportation system," Transportation Research Part C: Emerging Technologies, vol. 105, pp. 580-598, 2019.

[35] M. Zhou, S. Ge, J. Liu, H. Dong, and F.-Y. Wang, "Field observation and analysis of waiting passengers at subway platform - a case study of Beijing subway stations," Physica A: 
Statistical Mechanics and Its Applications, vol. 556, Article ID 124779, 2020.

[36] C. Wang, D. Mu, F. Zhao, and J. W. Sutherland, "A parallel simulated annealing method for the vehicle routing problem with simultaneous pickup-delivery and time windows," Computers \& Industrial Engineering, vol. 83, pp. 111-122, 2015.

[37] A. Kumar, P. Srikanth, A. Nayyar, G. Sharma, R. Krishnamurthi, and M. Alazab, "A novel simulatedannealing based electric bus system design, simulation, and analysis for Dehradun smart city," IEEE Access, vol. 8, Article ID 89395, 2020.

[38] A. Pessoa, R. Sadykov, and E. Uchoa, "Enhanced Branch-Cutand-Price algorithm for heterogeneous fleet vehicle routing problems," European Journal of Operational Research, vol. 270, no. 2, pp. 530-543, 2018.

[39] M. Cheikh, M. Ratli, O. Mkaouar, and B. Jarboui, “A variable neighborhood search algorithm for the vehicle routing problem with multiple trips," Electronic Notes in Discrete Mathematics, vol. 47, pp. 277-284, 2015.

[40] J. Liang, S. D. Cairano, and R. Quirynen, "Early termination of convex QP solvers in mixed-integer programming for realtime decision making," IEEE Control Systems Letters, vol. 5, no. 4, pp. 1417-1422, 2021.

[41] I. Soares, M. J. Alves, and C. H. Antunes, "A deterministic bounding procedure for the global optimization of a bi-level mixed-integer problem," European Journal of Operational Research, vol. 291, no. 1, pp. 52-66, 2021.

[42] C. Changdar, R. K. Pal, G. S. Mahapatra, and A. Khan, "A genetic algorithm based approach to solve multi-resource multi-objective knapsack problem for vegetable wholesalers in fuzzy environment," Operational Research, vol. 20, no. 3, pp. 1321-1352, 2018.

[43] A. Yildizeli and S. Cadirci, "Multi-objective optimization of multiple impinging jet system through genetic algorithm," International Journal of Heat and Mass Transfer, vol. 158, Article ID 119978, 2020.

[44] D. G. Dilip, S. Panda, and J. Mathew, "Characterization and parametric optimization of micro-hole surfaces in microEDM drilling on inconel 718 superalloy using genetic algorithm," Arabian Journal for Science and Engineering, vol. 45, no. 7, pp. 5057-5074, 2020.

[45] P. A. Grudniewski and A. J. Sobey, "Benchmarking the performance of genetic algorithms on constrained dynamic problems," Natural Computing, 2020.

[46] X. You, F. Hu, S. Dong, Y. Takahashi, and D. Shiode, "Shape optimization approach for cambered otter board using neural network and multi-objective genetic algorithm," Applied Ocean Research, vol. 100, Article ID 102148, 2020.

[47] C. A. Marín Moreno, L. M. E. Falcón, R. I. Bolaños, A. Subramanian, A. H. Escobar Zuluaga, and M. G. Echeverri, "A hybrid algorithm for the multi-depot vehicle scheduling problem arising in public transportation," International Journal of Industrial Engineering Computations, vol. 10, pp. 361-374, 2019.

[48] Y. Xiao and A. Konak, "A genetic algorithm with exact dynamic programming for the green vehicle routing \& scheduling problem," Journal of Cleaner Production, vol. 167, pp. 1450-1463, 2017. 